\title{
UNIVERSITY OF WAIKATO
}

\author{
Hamilton
}

New Zealand

Okun's Law, Asymmetries and

Jobless Recoveries in the United States:

A Markov-Switching Approach

Mark Holmes

Brian Silverstone

\section{Department of Economics}

\section{Working Paper in Economics 6/05}

December 2005

\author{
Mark Holmes \\ Brian Silverstone \\ Economics Department \\ Private Bag 3105 \\ University of Waikato \\ Hamilton, New Zealand \\ Tel: +64 (0) 7-838-4045 \\ Fax: +64 (0) 7-838-4331 \\ Email: holmesmj@waikato.ac.nz \\ Email: silver@waikato.ac.nz
}

Web: http://www.mngt.waikato.ac.nz 


\begin{abstract}
This paper offers a new perspective on Markov regime-switching approaches to asymmetries in Okun's law by modeling the existing approaches as special cases. Prevailing models assume either asymmetry between unemployment and output across regimes or asymmetry within a single regime. Our specification combines both approaches. Our empirical results give an insight into the apparent 'jobless recovery’ experiences that began in the United States in 1991 and 2001.
\end{abstract}

\title{
Keywords
}

Okun's law

Markov-switching

asymmetry

jobless recoveries

\section{JEL Classification}

C22; E32

\section{Acknowledgements}

We are grateful for helpful comments from an anonymous referee and participants at the 2005 New Zealand Association of Economists Conference. Remaining errors are our own. 


\section{Introduction}

In his well-known contribution on potential output, Arthur Okun (1962) gave three explanations for his empirical finding of an inverse relationship between the unemployment rate and output. His explanations were induced changes in labour force participation, hours worked and productivity. In short, recoveries create employment, and conversely. More recently, the literature has focussed on the possibility that asymmetries exist in the Okun relationship. Explanations include factor substitution, changes in labour force participation and sectoral growth rates, asymmetric adjustment costs between expanding and contracting firms and the role of mismatch (see Harris and Silverstone 2001).

Asymmetry in the Okun relationship has been considered from two perspectives. First, asymmetries occur when equal absolute increases and decreases in output lead to different responses in unemployment. An example is Silvapulle et al. (2004) who estimate Okun coefficients of -0.25 and -0.61 with respect to increases and decreases in American cyclical output between 1947 and 1999. Secondly, asymmetry occurs where a symmetric response of unemployment to output depends on whether or not the economy is in an expansionary or recessionary regime. Cuaresma (2003), for example, applies Markov switching models to American data (1965-1999) and estimates Okun coefficients of -0.20 and -0.44 with respect to increasing and decreasing output regimes.

In this study, we use Markov switching methodology to model regime-dependent Okun coefficients where the duration of each regime depends on the state of the economy. Compared to the existing literature, we estimate two Okun coefficients for each regime corresponding to whether cyclical output is above or below trend. To our knowledge, our paper is the first study to investigate both types of asymmetry using Markov regime-switching methodology. As a result, we offer a more complete account of asymmetry in Okun's law as well as insights into experiences such as ‘jobless recoveries’ in the United States. 


\section{Modelling Asymmetries in the Okun Relationship}

Suppose a discrete random variable $S_{t}$ takes two possible values $\left[S_{t}=(0,1)\right]$ and serves as an indicator for the state of the economy at time $t$. Let $u^{c}$ denote the cyclical unemployment rate as the difference between the observed and trend unemployment rates. Let $y^{c+}$ and $y^{c-}$ denote positive and negative cyclical output as the difference between the natural logarithms of observed output and trend output. The expected cyclical component of the unemployment rate, conditional on the value of $S_{t}$, is given by a generalisation of the linear specification in Moosa (1997):

$$
\begin{aligned}
E\left(u_{t}^{c} \mid S_{t}\right)= & {\left[\left(1-S_{t}\right) \mu_{0}+S_{t} \mu_{1}\right]+\left(1-S_{t}\right) \beta_{0}^{+} y_{t}^{c+}+\left(1-S_{t}\right) \beta_{0}^{-} y_{t}^{c-} } \\
& +S_{t} v_{0}^{+} y_{t}^{c+}+S_{t} v_{0}^{-} y_{t}^{c-}+\left(1-S_{t}\right) \sum_{i=1}^{l} \xi_{i} u_{t-i}^{c}+S_{t} \sum_{i=1}^{l} \tau_{i} u_{t-i}^{c}+\varepsilon_{t}
\end{aligned}
$$

where $\varepsilon_{t} \sim$ i.i.d.N $\left(0, \sigma_{\varepsilon}^{2}\right)$ and the unobserved indicator variable, $S_{t}$, evolves according to the first-order Markov-switching process described in Hamilton (1989):

$$
\begin{aligned}
& P\left[S_{t}=1 \mid S_{t-1}=1\right]=p \\
& P\left[S_{t}=0 \mid S_{t-1}=1\right]=1-p \\
& P\left[S_{t}=0 \mid S_{t-1}=0\right]=q \\
& P\left[S_{t}=1 \mid S_{t-1}=0\right]=1-q \\
& 0<p<1 \quad 0<q<1
\end{aligned}
$$

where $p$ and $q$ are the fixed transition probabilities of being in Regime 0 or 1 , respectively.

Equation (1) features four Okun coefficients, namely, $\beta_{0}^{+}, \beta_{0}^{-}, v_{0}^{+}, v_{0}^{-}$. They are shown in Table 1. A priori, we expect $\beta_{0}^{+}, \beta_{0}^{-}, v_{0}^{+}, v_{0}^{-}<0$ where cyclical unemployment responds negatively to cyclical output in either expansionary or recessionary regimes. These coefficients reflect the deepness of the relationship between these variables. This representation of Okun asymmetry can be compared to existing Markov-based studies that make no distinction between positive and negative values in cyclical output thereby imposing symmetry within each regime. 
Table 1

Four Okun Coefficients

Expansion in output $\left(y^{c+}\right) \quad$ Recession in output $\left(y^{c-}\right)$

Regime 0: Expansionary

Unemployment rate below trend

$$
u^{c}=\left(u-u^{t}\right)<0 \quad \beta_{0}^{+} \quad \beta_{0}^{-}
$$

Regime 1: Recessionary

Unemployment rate above trend $u^{c}=\left(u-u^{t}\right)>0$

$v_{0}^{+} \quad v_{0}^{-}$

In common with earlier Markov studies, we investigate the extent to which the state of the economy (upswing or downswing) is responsible for pushing the economy into Regime 0 or Regime 1. Extending the fixed two-state Markov-switching chain to allow for the possibility of time-varying transition probabilities enables us to specify:

$$
\begin{aligned}
& P\left[S_{t}=1 \mid S_{t-1}=1, \Delta y_{t}, \Delta y_{t-1}, \Delta y_{t-2}, \cdots\right]=p_{t}=\Phi\left(\delta_{0}+\sum_{i=1}^{m} \delta_{i} \Delta y_{t-i}\right) \\
& P\left[S_{t}=0 \mid S_{t-1}=0, \Delta y_{t}, \Delta y_{t-1}, \Delta y_{t-2}, \cdots\right]=q_{t}=\Phi\left(\gamma_{0}+\sum_{i=1}^{n} \gamma_{i} \Delta y_{t-i}\right)
\end{aligned}
$$

where $\Phi(\cdot)$ refers to the cumulative density function of the standard normal distribution. It ensures that the time-varying transition probabilities $p_{t}$ and $q_{t}$ lie in the open interval $(0,1)$. The relationships expressed in (3) reflect the duration of the Okun relationships expressed in (1). Estimation is based on four models.

Model I: Fixed Transition Probabilities (FTP) model.

This is the Hamilton Markov-switching specification represented by the restrictions

$$
\beta_{0}^{+}=\beta_{0}^{-}=v_{0}^{+}=v_{0}^{-}=\delta_{1}=\gamma_{1}=0
$$

Under these restrictions, there is no role for cyclical output in either the mean equation or the determination of the transition probabilities. 
Model II: FTP + mean model.

In this specification, cyclical output enters the mean equations only, that is,

$$
\beta_{0}^{+} \neq 0, \beta_{0}^{-} \neq 0, v_{0}^{+} \neq 0, v_{0}^{-} \neq 0, \delta_{1}=\gamma_{1}=0
$$

Model III: Time-varying Transition Probabilities (TVP) model.

In this specification, only the growth in cyclical output enters the transition probabilities, that is,

$$
\beta_{0}^{+}=\beta_{0}^{-}=v_{0}^{+}=v_{0}^{-}=0, \delta_{1} \neq 0, \gamma_{1} \neq 0 \text {. }
$$

Model IV: TVP + mean model.

This is a generalised specification where cyclical output and the growth in cyclical output enter both the mean and the transition probabilities, that is,

$$
\beta_{0}^{+} \neq 0, \beta_{0}^{-} \neq 0, v_{0}^{+} \neq 0, v_{0}^{-} \neq 0, \delta_{1} \neq 0, \gamma_{1} \neq 0
$$

Estimation is by maximum likelihood using the non-linear filter algorithm in Hamilton (1989). An important by-product of the estimation procedure is the computation of the filter probabilities that allow us to draw conclusions about the unobserved state for each period. Given that Model IV nests Models I, II and III, we are able to compare and contrast the appropriateness of these models in explaining the relevance of Okun's law to United States data.

\section{Data and Estimation}

Seasonally adjusted data for United States real GDP and unemployment rate (1963:1 to 2004:3) are taken from the OECD database and detrended using the Markovswitching model. The resulting series for cyclical output $\left(y^{c}\right)$ and the cyclical unemployment rate $\left(u^{c}\right)$ are illustrated in Figure 1. 
Figure 1

United States Cyclical Output and Unemployment Rate (percent)

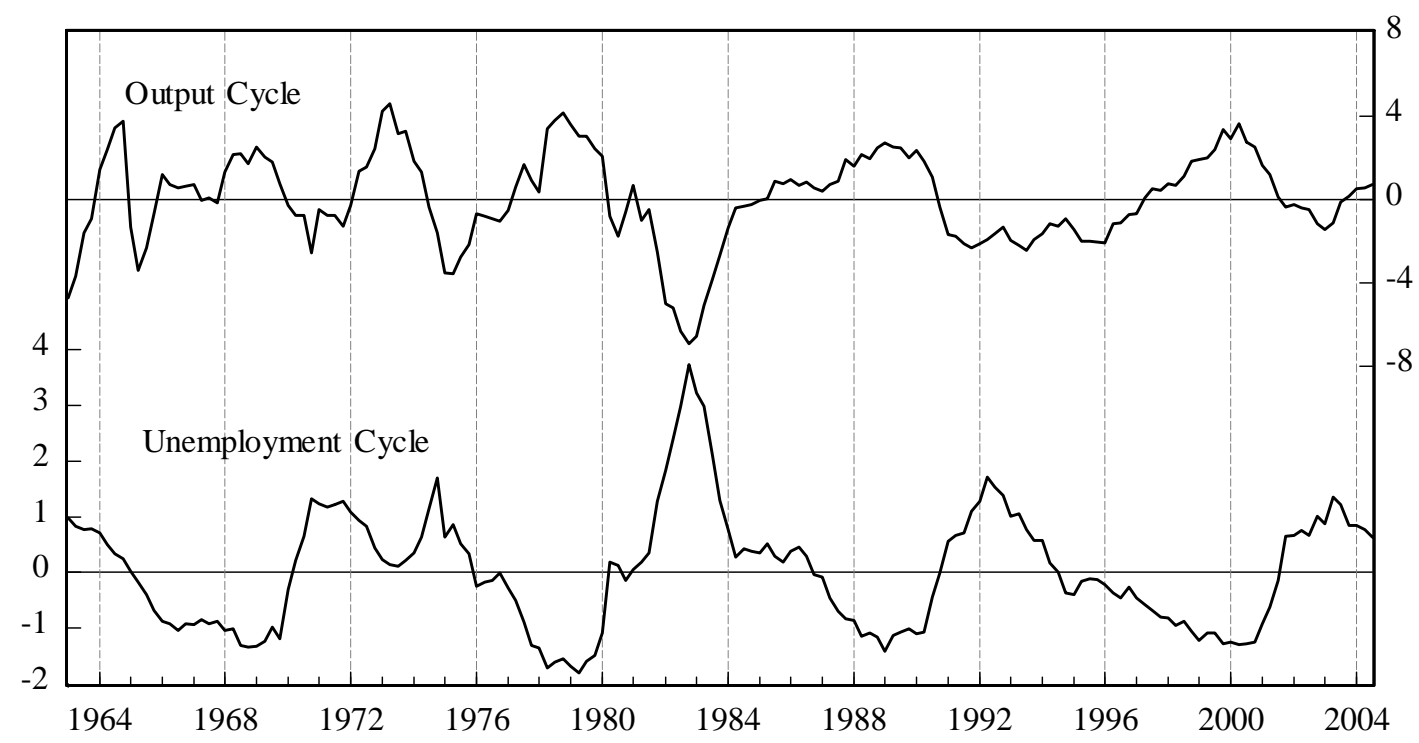

The estimates of the log likelihood values associated with each model are reported in Table 2. Having started with a maximum of six lags, the inclusion of one lagged value of $u^{c}$ (together with contemporaneous $y^{c+}$ and $y^{c-}$ in the conditional mean process and lagged $\Delta y$ in the state transition probability process) was found to be acceptable. Compared with the benchmark specification (Model I), the generalised model (Model IV) achieves a significant improvement in the likelihood function according to conventional likelihood ratio tests. Moreover, the likelihood ratio statistic of 51.204 is distributed as $\chi^{2}(6)$ on the null. In comparing Models IV and II, the likelihood ratio statistic of 9.714 is distributed as $\chi^{2}(2)$ on the null. These results lead to the choice of Model IV as the preferred model.

Table 2

Log likelihood Values for Each Model

\begin{tabular}{lr}
\hline Model I & -12.317 \\
Model II & 8.428 \\
Model III & -3.620 \\
Model IV & 13.285 \\
\hline
\end{tabular}


Table 3 reports the estimation of the time-varying transition probabilities + mean model. These results passed tests concerning autocorrelation and normality. We find that the mean cyclical unemployment rate is lowest in Regime $0\left(\mu_{0}<\mu_{1}\right)$. This suggests that Regimes 0 and 1 may be described as outcomes where unemployment is below and above trend, respectively. Across the two regimes, the four statedependent Okun coefficients are all negative with three coefficients significant at the five percent level or better. The exception is $\beta_{0}^{+}$, where positive movements in cyclical output in Regime 0 are associated with below trend cyclical unemployment. Here, significance occurs only at the ten per cent level.

Further tests result in the rejection of the null hypotheses $v_{0}^{+}=v_{0}^{-}, \beta_{0}^{-}=v_{0}^{-}$and $\beta_{0}^{+}=v_{0}^{+}$. This outcome confirms the presence of two forms of asymmetry. First, unlike existing regime-switching investigations, such as Cuaresma (2003), we find asymmetry within Regime 1 . Evidence that $v_{0}^{+}>v_{0}^{-}$implies that a given increase in cyclical output during the regime where unemployment is above trend has a smaller impact on the cyclical unemployment rate than a decrease in cyclical output of equal absolute magnitude. Secondly, there is asymmetry across regimes. Our results indicate that $\beta_{0}^{-}>v_{0}^{-}$and $\beta_{0}^{+}>v_{0}^{+}$. This implies that the unemployment rate is more sensitive to movements in cyclical output in the more recessionary Regime 1. Regarding the estimated mean equations, the null, $\beta_{0}^{+}=\beta_{0}^{-}$, is accepted at the five percent significance level. This suggests that within-regime asymmetry is not present in the expansionary Regime 0 . It is in this respect only that a symmetric Okun coefficient is appropriate.

Regarding the transition probabilities for each state, we find $\delta_{1}>0$ and $\gamma_{1}=0$. This outcome supports the hypothesis of a stronger response from unemployment to output on the downswing. Moreover, decreases (increases) in the growth of output decrease (increase) the duration of Regime 0 when the unemployment rate is below trend. This is the regime characterised by Okun coefficients with the least sensitivity of cyclical unemployment to cyclical output. 
Table 3

Estimation of the generalised regime-switching model (Model IV)

\begin{tabular}{lll}
\hline Coefficient & Variable & Estimate \\
\hline$\sigma_{\varepsilon}$ & & $0.037^{* * *}$ \\
Regime 0: Expansionary & & \\
$\left(1-S_{t}\right) \mu_{0}$ & 1 & $-0.135^{* * * *}$ \\
$\left(1-S_{t}\right) \xi_{1}$ & $u_{t-i}^{c}$ & $0.848^{* * *}$ \\
$\left(1-S_{t}\right) \beta_{0}^{-}$ & $y_{t}^{c-}$ & $-0.023^{* *}$ \\
$\left(1-S_{t}\right) \beta_{0}^{+}$ & $y_{t}^{c+}$ & $-0.025^{*}$ \\
Regime 1: Recessionary & & \\
$S_{t} \mu_{1}$ & 1 & $0.302^{* * *}$ \\
$S_{t} \tau_{1}$ & $u_{t-i}^{c}$ & $0.624^{* * *}$ \\
$S_{t} v_{0}^{-}$ & $y_{t}^{c-}$ & $-0.193^{* * *}$ \\
$S_{t} v_{0}^{+}$ & $y_{t}^{c+}$ & $-0.084^{* * *}$ \\
Transition Probabilities & & \\
$\delta_{0}$ & 1 & $1.599^{* * *}$ \\
$\delta_{1}$ & $\Delta y_{t-1}$ & $2.763^{* * *}$ \\
$\gamma_{0}$ & 1 & $1.908^{* * *}$ \\
$\gamma_{1}$ & $\Delta y_{t-1}$ & 0.618 \\
Tests of Restrictions & & \\
$\beta_{0}^{+}=\beta_{0}^{-}$ & & 0.031 \\
$v_{0}^{+}=v_{0}^{-}$ & & $10.070^{* * *}$ \\
$\beta_{0}^{-}=v_{0}^{-}$ & & $96.490^{* * *}$ \\
$\beta_{0}^{+}=v_{0}^{+}$ & & $3.146^{*}$ \\
\hline
\end{tabular}

Estimates are for the regime-switching model described by equations (1) and (3). ***, ** and * denote rejection of a zero null at the 1, 5 and 10 percent significance levels. Chi-square statistics are reported for the hypothesis tests.

Our findings can be used to reflect on the decades commencing 1991 and 2001 when the United States experienced growth in real output unaccompanied by the expected employment gains. Explanations for these apparent 'jobless recoveries' include data measurement issues, sectoral reallocation, new technologies, organizational dynamics, productivity changes, just-in-time hiring and foreign outsourcing, an increase in self-employment, changes in labour supply and hours 
worked, changes in job creation and destruction rates and the impact of health care costs, drought, contractions in investment expenditure, stock market behaviour, monetary and fiscal policy and uncertainty regarding growth prospects. There is relatively little consensus regarding the most important influences. (See Aaronson et al. 2004 for a helpful survey).

Rather than seeking either period-specific or structural explanations for these jobless recoveries, we use the new perspective on asymmetries in Okun's law in this paper to seek insights from American cyclical experience. This perspective suggests that the notion of 'jobless recoveries' to explain the two most recent American experiences may be exaggerated because a relatively expansion-insensitive Okun coefficient is nothing new for the American economy. This is illustrated in Figure 2. It plots the inferred American probabilities of being in Regime 0, that is, the probability of being in the expansionary regime with a below-trend unemployment rate. For 1991 and 2001 (and indeed for 1970 and, to some extent, 1982) there was a very low probability of the United States being in Regime 0 and a very high probability of being in Regime 1 which is characterised by a relatively prolonged and above-trend unemployment rate.

Figure 2

Model IV: Inferred probabilities for being in Regime 0

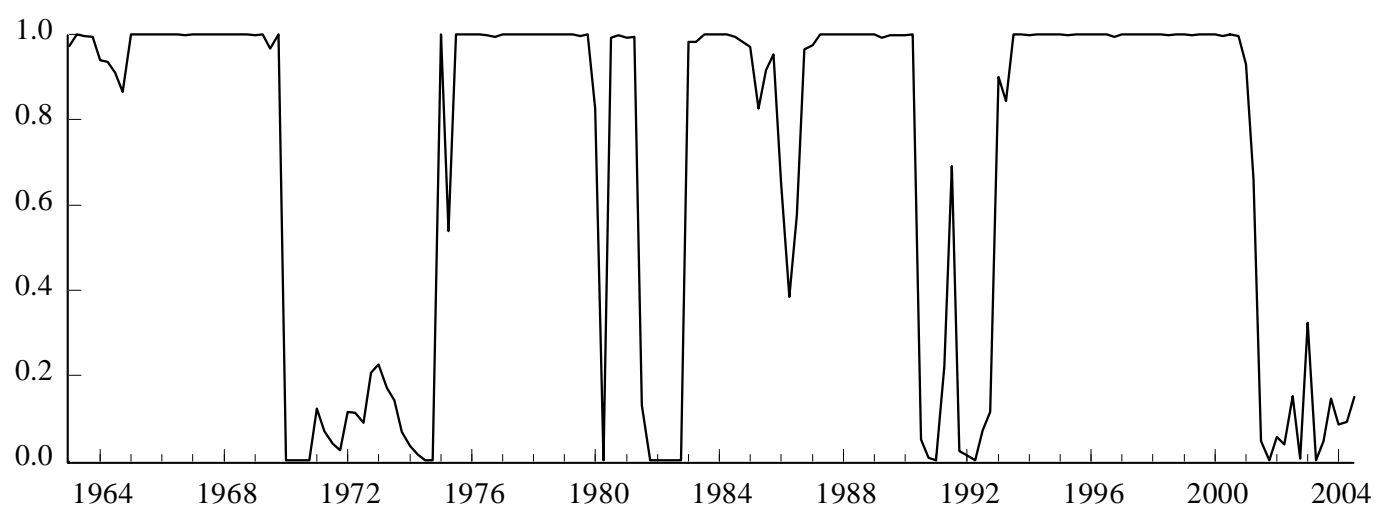

The common cyclical feature underlying the 1970, 1991 and 2001 jobless recoveries is, perhaps, the one identified by Koenders and Rogerson (2005). They use the theory of dynamic organizations, or inter-temporal restructuring, to show that recoveries from recessions following long expansions will have slower employment 
growth. Figure 1 illustrates their view. Take, for example, the long expansion prior to 2001. In 2002, output is not far below trend. By 2003, output rises above trend. This recovery, however, is accompanied by an unemployment rate that still exceeds its trend value. As Figure 2 suggests, the 2002 recovery is characterised by an economy most likely remaining in recessionary Regime 1, with a small, though nonetheless significant, Okun coefficient of $v_{0}^{+}=-0.084$.

\section{Conclusions}

In this paper, we have provided a new perspective on asymmetries in Okun's law. Compared to other studies using the Markov regime-switching model, we have identified the presence of asymmetries within and across regimes. Our empirical work has shown that a significant inverse relationship between cyclical output and unemployment can exist in United States expansionary regimes. Given this finding, the notion of jobless recoveries may be exaggerated.

\section{References}

Aaronson, D., E.R. Rissman and D.G. Sullivan, 2004, Assessing the jobless recovery, Federal Reserve Bank of Chicago, Economic Perspectives 28, 2-20.

Cuaresma, J.C. 2003, Okun’s law revisited, Oxford Bulletin of Economics and Statistics 65, 439-451.

Hamilton, J.D. 1989, A new approach to the economic analysis of nonstationary time series and the business cycle, Econometrica 57, 357-384.

Harris, R. and B. Silverstone, 2001, Testing for asymmetry in Okun's law: A cross-country comparison, Economics Bulletin 5, 1-13.

Koenders, K. and R. Rogerson, 2005, Organizational dynamics over the business cycle: a view on jobless recoveries, Federal Reserve Bank of St. Louis, Review 87, 555-579.

Moosa, I.A. 1997, A cross-country comparison of Okun's coefficient, Journal of Comparative Economics 24, 335-356.

Okun, A.M. 1962, Potential GNP: Its measurement and significance, American Statistical Association, Proceedings of the Business and Economics Statistics Section, 98-104.

Silvapulle, P., I.A. Moosa and M.J. Silvapulle, 2004, Asymmetry in Okun's law, Canadian Journal of Economics 37, 353-374. 